COELIAC DISEASE

\title{
Autoantibodies of patients with coeliac disease are insufficient to block tissue transglutaminase activity
}

\author{
W Dieterich, D Trapp, B Esslinger, M Leidenberger, J Piper, E Hahn, D Schuppan
}

Gut 2003;52:1562-1566

See end of article for authors' affiliations ....................

Correspondence to: Professor Dr D Schuppan, Department of Medicine I, University of ErlangenNuernberg, Ulmenweg 18, 91054 Erlangen, Germany; detlef.schuppan@

med1.imed.uni-erlangen.de

Accepted for publication 13 July 2003
Background and aims: Coeliac disease (CD) is characterised by the presence of autoantibodies against tissue transglutaminase ( $\mathrm{tTG}$ ), the endomysial autoantigen. This study was performed to determine the effect of purified autoantibodies on the enzymatic activity of $\mathrm{TTG}$.

Methods: Total $\lg A$ and $\lg G$ class antibodies and purified anti-tTG autoantibodies were isolated from sera of untreated patients with CD and controls. The inhibitory capacity of the antibodies on ITG activity was checked by a fluorometric assay based on the incorporation of monodansyl cadaverine into casein and by tTG-catalysed cross linking of biotinylated cadaverine to gliadin.

Results: The enriched $\lg A$ and $\lg G$ fractions of five patients with $C D$ and three controls resulted in no significantly different inhibition of enzymatic activity. In contrast, the use of affinity purified anti-tTG autoantibodies of 12 patients with CD led to a dose dependent reduction of TTG activity, compared to control immunoglobulins $(n=6)$. However, the remaining activity was sufficient for cross linking of cadaverine into gliadin, and enzymatic tTG activity was only blocked completely by high concentrations of a monoclonal antibody, which is directed to the active centre of tTG.

Conclusions: Despite a partial inhibitory effect of isolated anti-tTG autoantibodies from patients with CD, residual enzymatic activity remains sufficiently high to cast doubt on their in vivo relevance.
C oeliac disease $(C D)$ is a gluten sensitive enteropathy caused by the ingestion of wheat gliadin or related storage proteins in rye and barley. ${ }^{12}$ Coeliac disease is characterised by the presence of antibodies against the etiological agent gliadin ${ }^{3}$ and especially tissue transglutaminase (tTG), which was identified as endomysial autoantigen in CD. ${ }^{5}$ tTG typically cross links proteins by catalysing the formation of intermolecular bonds but also can deamidate glutamine residues when primary glutamine acceptors are missing. ${ }^{67}$

The autoantigen tTG plays an important role in coeliac disease pathogenesis due to its ability to deamidate gliadin peptides at well defined glutamines. These modified gliadin peptides show better binding to HLA-DQ2 or -DQ8 molecules which results in more efficient $\mathrm{T}$ cell proliferation. ${ }^{8-16}$

The central role of tTG in CD pathogenesis is further emphasised by the high association of the autoantibodies to tTG with active CD reaching nearly $100 \%$ specificity and sensitivity. ${ }^{17-22}$ tTG autoantibodies have also been held as instrumental in the observed intestinal damage of $\mathrm{CD}$, due to their potential to interfere with the tTG dependent activation of transforming growth factor $\beta$, thus affecting intestinal epithelial differentiation and cell matrix interactions. ${ }^{23}$ Since findings regarding the direct inhibitory potential of antibodies from patients with CD are controversial, ${ }^{24}$ we aimed to further define the capacity of the autoantibodies against tTG to block its catalytic activity. Based on our data we suggest a limited in vivo role of these autoantibodies.

\section{METHODS}

\section{Antibody isolation}

For IgA class antibodies, sera from five biopsy proven patients with active $C D$ and three healthy controls were diluted $1: 2$ with $0.1 \mathrm{M}$ sodium phosphate, pH 7.0 and incubated with Kaptiv-AE agarose (Tecnogen, Piana di Monte Verna, Italy) for $1 \mathrm{~h}$ at room temperature. The agarose was washed and retained antibodies were released with $0.1 \mathrm{M}$ acetic acid, $\mathrm{pH} 4.0$, and rapidly neutralised with $1 / 10$ volume of $1 \mathrm{M}$
Tris-HCl, pH 9.0. For isolation of IgG antibodies protein A Sepharose (Amersham Pharmacia Biotech, Freiburg, Germany) was swollen in $0.1 \mathrm{M}$ Tris- $\mathrm{HCl}$, pH 8.0, and incubated for $\mathrm{l} \mathrm{h}$ at room temperature with sera from five untreated patients with $\mathrm{CD}$ and three control subjects adjusted to $\mathrm{pH} 8.0$ by addition of $1 / 10$ volume $1 \mathrm{M}$ Tris$\mathrm{HCl}, \mathrm{pH} 8,0$. After washing with $0.1 \mathrm{M}$ Tris-HCl, $\mathrm{pH} 8.0$, and $0.01 \mathrm{M}$ Tris-HCl, $\mathrm{pH} 8.0$, bound antibodies were eluted with $0.1 \mathrm{M}$ glycine, $\mathrm{pH} 2.5$, and immediately neutralised with $1 / 5$ volume of $1 \mathrm{M}$ Tris- $\mathrm{HCl}, \mathrm{pH} 8.0$.

\section{Isolation of human autoantibodies to tTG}

The plasmid pJLP4 expressing human tTG (provided by JL Piper and Ch Khosla, Stanford, USA) was expressed in Escherichia coli Tuner DE3. The purification of recombinant human tTG was performed as described with minor variations. ${ }^{26}$ After dialysis against binding buffer $(0.1 \mathrm{M}$ sodium bicarbonate, $0.5 \mathrm{M} \mathrm{NaCl}, \mathrm{pH} 8.3$ ) the recombinant tTG was covalently coupled to CNBr-activated CL4B-Sepharose (Amersham Pharmacia Biotech) according to the manufacturer's instructions. For isolation of autoantibodies against tTG the sera of 12 different patients with active CD were diluted 1:5 in phosphate buffer, $\mathrm{pH}$ 7.4, and incubated with the tTG coupled Sepharose. Several washing steps were followed by elution of the anti-tTG autoantibodies with $0.1 \mathrm{M}$ glycine $\mathrm{pH} 2.5$, which were instantly neutralised with 1/5 volume $1 \mathrm{M}$ Tris- $\mathrm{HCl}, \mathrm{pH}$ 8.0. The titre against tTG was checked by ELISA as described before. ${ }^{17}$

All antibodies were intensively dialysed against $0.05 \mathrm{M}$ Tris- $\mathrm{HCl}, 0.15 \mathrm{M} \mathrm{NaCl}, \mathrm{pH} 7.5$, and protein content was determined by the method of Bradford (Bio-RAD, Munich, Germany). The purity of IgA and IgG antibody fractions was

\footnotetext{
Abbreviations: ab, antibody; CD, coeliac disease; ELISA, enzyme linked immunosorbent assay; SDS-PAGE, sodium dodecyl sulfate polyacrylamide gel electrophoresis; $\mathrm{TTG}$, tissue transglutaminase
} 
confirmed by sodium dodecyl sulfate polyacrylamide gel electrophoresis (SDS-PAGE).

For additional control experiments a polyclonal goat antiguinea pig liver transglutaminase antibody (Biomol, Hamburg, Germany), and a monoclonal antibody against guinea pig transglutaminase (CUB 7402, Quartett, Berlin, Germany) were used.

\section{In vitro tTG activity test Incorporation of biotinylated cadaverine into gliadin}

Since gliadin is known as a good glutamine donor substrate for $\mathrm{tTG}$, the enzymatic activity of tTG was checked by cross linking gliadin (glutamine donor) with biotinylated cadaverine (glutamine acceptor). Therefore, $1 \mu \mathrm{g}$ of crude gliadin (Sigma, Taufkirchen, Germany) was incubated with $200 \mathrm{ng}$ biotinylated cadaverine (CovalAb, Lyon, France) and 0.5$1 \mu \mathrm{g}$ of human recombinant tTG in $0.1 \mathrm{M}$ Tris- $\mathrm{HCl}, 0.15 \mathrm{M}$ $\mathrm{NaCl}, 5 \mathrm{mM} \mathrm{CaCl}_{2}, \mathrm{pH} \mathrm{7.5}$, in a total volume of $100 \mu \mathrm{l}$. Cross linking was allowed for $2 \mathrm{~h}$ at $37^{\circ} \mathrm{C}$. For inhibition studies varying amounts of the corresponding antibodies were preincubated with tTG for $10 \mathrm{~min}$ at $37^{\circ} \mathrm{C}$ and the reaction was started by the addition of gliadin and cadaverine. The assay was stopped by addition of trichloroacetic acid at a final concentration of $10 \%$ at $4{ }^{\circ} \mathrm{C}$ over night. Precipitated proteins were run under reducing conditions in SDS-PAGE and transferred to nitrocellulose. The blot was blocked with $3 \%$ bovine serum albumin in $0.1 \mathrm{M}$ Tris- $\mathrm{HCl}, 0.15 \mathrm{M} \mathrm{NaCl}$, $\mathrm{pH} 7.5$, and further incubated with a covalently coupled streptavidine-alkaline phosphatase conjugate (Sigma). Colour was developed with 5-bromo-4-chloro-3-indolyl phosphate and nitroblue-tetrazolium (SIGMA FAST tablets, Sigma).

\section{Kinetic activity assay}

The enzymatic activity of tTG in the presence of antibodies was quantified by measurement of the incorporation of monodansyl cadaverine (glutamine acceptor) into $\alpha$-casein (glutamine donor). The incorporation of monodansyl cadaverine (N-(5-aminopentyl)-5-dimethylamino-1-naphthalinsulfonamide) (Sigma) into bovine $\alpha$-casein results in an increased intensity of fluorescence of the dansyl group as described. ${ }^{27}$ Although gliadin is also a suitable substrate for this assay, we used $\alpha$-casein as substrate for tTG because of its better solubility in neutral buffers. $\alpha$-Casein $(17 \mu \mathrm{M})$ was incubated with $30 \mu \mathrm{M}$ monodansyl cadaverine in a total volume of $100 \mu \mathrm{l} 0.1 \mathrm{M}$ Tris- $\mathrm{HCl}, 0.15 \mathrm{M} \mathrm{NaCl}, 5 \mathrm{mM} \mathrm{CaCl}_{2}$, $\mathrm{pH}$ 7.5. For inhibition studies the antibodies were added at different concentrations ranging from $0.5-5.5 \mu \mathrm{g}$. The reaction was started by addition of $0.5 \mu \mathrm{g}$ human recombinant tTG at $37^{\circ} \mathrm{C}$. Excitation was at $360 \mathrm{~nm}$ and the increase in fluorescence was measured at $550 \mathrm{~nm}$ with a fluorescence spectrophotometer (Photon Technology International, Canada). Since human tTG rapidly lost activity at $37^{\circ} \mathrm{C}$ the slope was determined for only 2 min after addition of tTG. tTG activity was calculated as the percentage of remaining activity in correlation to control experiments without addition of antibodies.

\section{Statistics:}

The Mann-Whitney $U$ test was used to analyse the differences of inhibitory capacity of anti-tTG antibodies of patients with CD and immunoglobulins of controls.

\section{RESULTS}

\section{Influence of serum on ITG activity}

A concentration dependent inhibitory effect on tTG activity was noticed when the sera of patients with $\mathrm{CD}$ were added at concentrations of $1 \%, 5 \%$, or $10 \%$ to the fluorometric activity assay. The rate of inhibition of tTG activity ranged from $25-58 \%$ with serum concentrations between $1 \%$ and $10 \%$ (data not shown). However, the same values were also noticed with the control sera, therefore indicating a non-specific inhibitory effect of serum on tTG activity in general.

\section{Effect of isolated $\lg A$ and isolated $\lg G$ antibodies}

Impurities of the isolated $\operatorname{IgG}$ with $\operatorname{IgA}$ and vice versa were negligible as checked in the IgG- and IgA-specific anti-tTG ELISA, respectively (data not shown).

There was a broad range of inhibition on tTG activity when using the purified IgA and IgG fractions of five patients with $\mathrm{CD}$, reaching up to $60 \%$ at high concentrations (4.5-5.5 fold molar antibody excess relative to tTG) in some of the sera (mean 22\% for IgA and 35\% for IgG). However, there was no significant difference in comparison to total IgA or IgG fractions of three non-coeliac controls (data not shown). This rather suggests non-specific interactions than specific inhibition of tTG activity by total serum IgA or IgG.

\section{Effect of purified anti-tTG autoantibodies}

Whereas a commercially available polyclonal goat antiguinea pig tTG antibody showed no relevant inhibition of tTG activity in the fluorometric assay, the application of the affinity purified anti-tTG autoantibodies of 12 untreated patients with CD (roughly equal quantities of which belong to the IgA and IgG class), caused a distinct and concentration dependent inhibition of TTG activity. Although the inhibition reached up to $80 \%$ at an antibody to enzyme ratio of $5.5: 1(\mathrm{~mol} / \mathrm{mol})$, tTG activity could never be blocked completely and no positive correlation with anti-tTG titres was observed (table 1). In spite of a broad range of inhibitory capacity between different purified tTG autoantibodies from coeliac sera the inhibitory effect was significantly higher than that of immunoglobulin fractions of six non-coeliac controls. The remaining activity reached specific values with a mean of $66 \%$ when low (0.5-2 fold molar excess) and 46\% when high antibody concentrations were used (4.5-5.5 fold molar excess of antibodies over tTG), thus demonstrating a distinct inhibitory effect of the anti-tTG autoantibodies on tTG activity (fig 1).

tTG undergoes conformational changes in the presence of calcium ions. ${ }^{28}$ To determine to what extent the inhibitory effect of anti-tTG autoantibodies depends on the structural changes we preincubated tTG with $5 \mathrm{mM}$ calcium chloride for $5 \mathrm{~min}$ on ice. However this procedure had no influence on antibody inhibition (data not shown).

Table 1 Effect of varying concentrations of affinity purified autoantibodies from six different patients with $C D$ to tTG.

\begin{tabular}{lllll}
\hline & \multicolumn{4}{c}{ Fold molar excess of antibody to tTG } \\
\cline { 2 - 5 } Patients with CD & $\mathbf{0 . 5}$ & $\mathbf{1}$ & $\mathbf{2}$ & $\mathbf{5 . 5}$ \\
\hline CD 1 (163)* & - & 59 & 32 & 25 \\
CD 2 (70) & - & 30 & 45 & 22 \\
CD 3 (217) & - & 83 & 50 & 33 \\
CD 4 (100) & - & 70 & 35 & 44 \\
CD 5 (91) & - & 123 & 51 & 42 \\
CD 6 (91) & 123 & 85 & 63 & - \\
\hline
\end{tabular}

${ }^{*} \lg \mathrm{A}$ anti-tTG titres as determined by ELISA are shown in parenthesis. The values indicate the percentage of remaining TTG activity compared to basal tTG in the absence of inhibitory antibodies.

$C D$, coeliac disease; $\mathrm{tG}$, tissue transglutaminase. 


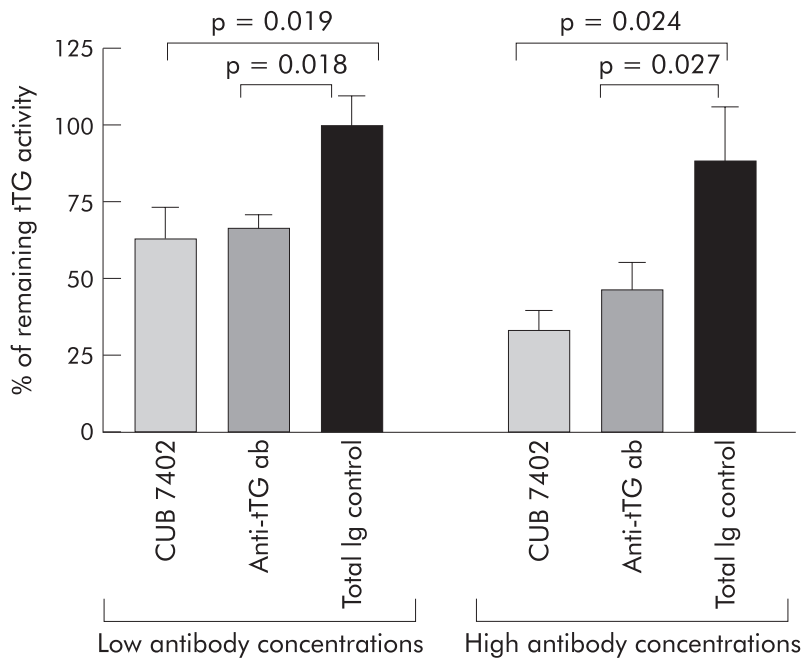

Figure 1 Inhibitory effect of affinity purified anti-tissue transglutaminase $(t T G)$ autoantibodies of patients with coeliac disease $(C D)$ $(n=12)$ and the monoclonal antibody (ab) CUB 7402 at low antibody concentrations (0.5-2 fold molar excess over +TG) and at high antibody concentrations (4.5-5.5 fold molar excess over TTG) compared to purified immunoglobulins of non-coeliac controls $(n=6)$. The data were calculated as percentage of remaining activity in relation to basal activity. The $p$ values for significant differences of mean values are indicated.

\section{Inhibitory effect of mouse monoclonal anti-tTG antibody}

The CUB 7402 antibody is described to map amino acids (aa) $447-478$ of tTG and inhibit its activity. Accordingly, the antibody clearly inhibited tTG activity resulting in a mean remaining activity of $62 \%$ at low antibody concentrations $(<2$ fold molar excess of antibody over tTG) and of $33 \%$ at high antibody concentrations (4.5-5.5 fold molar excess over tTG) when using the fluorometric assay. Although the region which is recognised by the antibody includes two potential calcium binding sites (aa 450 and 470$)^{29}$ the preincubation of tTG with calcium ions did not modify the results of this kinetic test.

\section{In vitro assay to determine the effect of residual tTG activity}

The fluorometric assay was most helpful to quantify the extent of the autoantibody inhibition. We observed a spontaneous decline in tTG activity up to $50 \%$ after preincubation of the enzyme without antibodies at $37^{\circ} \mathrm{C}$ for a short period of 5-15 min. This effect was more pronounced when the preincubation was done in a calcium free buffer (data not shown). Consequently, we performed the test without preincubation of tTG with the antibodies and the enzymatic activity was determined for only $2 \mathrm{~min}$ after addition of tTG, since the relation of fluorescence intensity to time was linear in this time frame. However, this assay yields no information about the remaining enzymatic activity.

Therefore, the tTG catalysed incorporation of biotinlabelled cadaverine into gliadin in the presence of the autoantibodies was determined. After preincubation of tTG with the antibodies for $10 \mathrm{~min}$ at $37^{\circ} \mathrm{C}$, the assay was performed for $2 \mathrm{~h}$ at $37^{\circ} \mathrm{C}$. Here, cross linking of cadaverine with gliadin results in protein complexes with molecular weights covering the whole range above $30 \mathrm{kDa}$ in SDSPAGE. The patterns of cross linked gliadins did not differ if tTG was preincubated in the test buffer for $10 \mathrm{~min}$ at

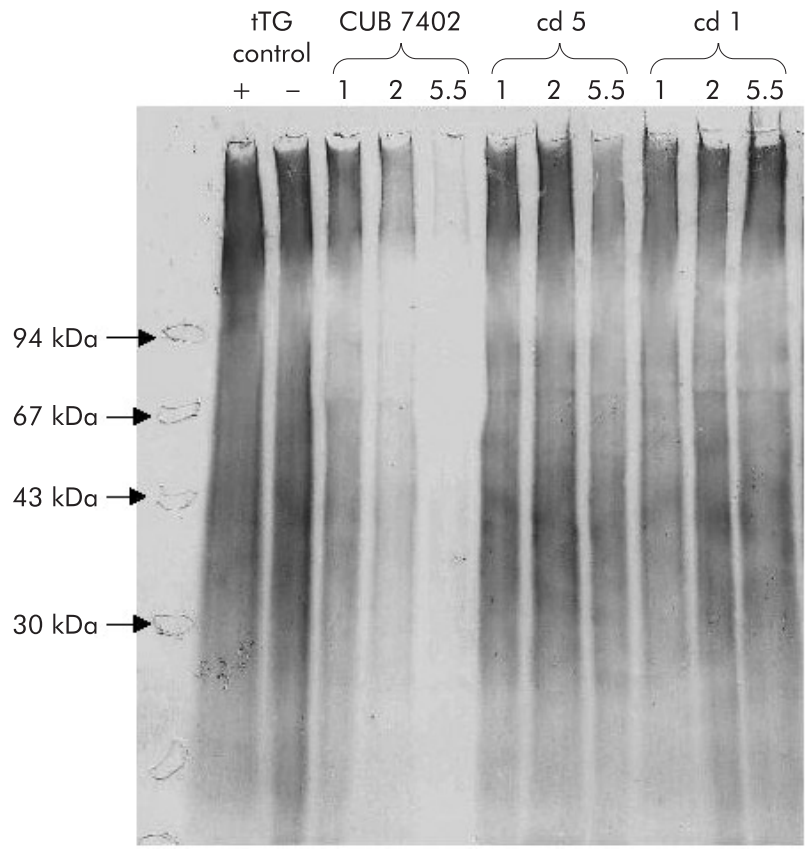

Figure 2 Tissue transglutaminase (tTG) catalysed cross linking of biotinlabelled cadaverine (glutamine acceptor) into gliadin (glutamine donor) to demonstrate the ITG activity. Shown is the detection of cadaverine gliadin complexes in a Western blot after separation by SDS-PAGE (12\%). The assay was performed for $2 \mathrm{~h}$ after preincubation of TTG with varying amounts of purified anti-tTG autoantibodies $(0.5-5.5$ fold molar excess over $\mathrm{TTG}$ ) from patients with coeliac disease (CD) (CD 1, CD 5) or monoclonal antibody CUB 7402 at $37^{\circ} \mathrm{C}$ for $10 \mathrm{~min}$. Except for CUB 7402 staining patterns were identical. The effect on residual enzymatic activity after preincubation of $\mathrm{TTG}$ was checked. The control experiments yielded the same staining pattern even if $\mathrm{TTG}$ was preincubated at $37^{\circ} \mathrm{C}$ for $10 \min (+)$ or not $(-)$.

$37^{\circ} \mathrm{C}$ or not, irrespective of the presence of increasing amounts of inhibitory antibodies (fig. 2). This indicates that when the cross linking reaction is allowed for a sufficient time the remaining overall enzymatic tTG activity is indistinguishable between uninhibited and partially inhibited enzyme.

In contrast, the monoclonal anti-tTG antibody CUB 7402 markedly reduced the catalytic activity of tTG and almost completely inactivated the enzyme at 5.5 fold molar excess over tTG (fig 2). This can be explained by the preincubation of tTG with CUB 7402 in this assay for 10 min which appears to be sufficient for the antibody-epitope recognition, while the fluorometric assay which shows 33\% residual activity reflects the beginning situation without preincubation.

\section{DISCUSSION}

Since tTG was identified as a CD autoantigen several studies stressed the importance of this enzyme in the pathogenesis of the disorder. Thus tTG expression is upregulated in the subepithelial lamina propria, ${ }^{8}{ }^{30}$ where tTG-induced deamidation of certain gliadin peptides can enhance their $\mathrm{T}$ cell stimulatory capacity via presentation by HLA-DQ2 or -DQ8. . $^{-1631}$

In this context the potential inhibitory capacity of the autoantibodies against tTG is of major interest. A former study suggested that total serum IgA of coeliac patients prevented tTG-induced activation of transforming growth factor $\beta$, resulting in a disturbed epithelial cell differentiation which is implied in the pathological damage of $\mathrm{CD} .{ }^{23}$ 
Recently, using a crude lysate of tTG-transfected MadinDarby canine kidney cells as source of tTG, the enzyme inhibitory capacity of total serum IgA and IgG and of recombinant monoclonal anti-tTG antibodies was underlined. ${ }^{25}$ In contrast, another study failed to demonstrate any inhibitory effect of total serum IgA and IgG of patients with $\mathrm{CD}$ when tested with purified human tTG. ${ }^{24}$ These results with total IgA and IgG class antibodies were confirmed by our data.

Therefore, the question of whether $\mathrm{CD}$ autoantibodies to tTG inhibit the enzymatic activity and thus have major physiological significance remains unresolved. Firstly, different tTG sources were used. Secondly, when measuring tTG activity, buffer reagents like glycine or acetic acid which are normally used to isolate the antibodies, have to be completely removed since even small amounts of these reagents strongly inhibit tTG activity. Thirdly, bioactive $\mathrm{tTG}$ is a very unstable protein. Thus incubation at $37^{\circ} \mathrm{C}$ leads to a marked decrease in enzymatic activity particularly in calcium free buffers (data not shown). In this context it must be emphasised that both the enriched IgA and IgG fractions as well as total serum of patients with CD and of non-coeliac controls block tTG activity (up to $60 \%$ in particular cases, possibly due to substrate competition). We could exclude human serum albumin as inhibitor but could not identify the (unspecific) inhibitory serum component(s).

However, when using the sensitive fluorometric assay and affinity purified anti-tTG autoantibodies, which belong to the IgA and IgG class in a nearly equal proportion, we could show a distinct and specific inhibition of tTG activity. This inhibition was dose-dependent and led to a mean residual activity of $46 \%$ when used at the highest autoantibody concentrations (4.5-5.5 fold molar excess over tTG). We obtained similar results when tTG was preincubated in calcium containing buffer on ice, but complete inhibition could never be achieved with the purified anti-tTG autoantibodies. This is in agreement with a report which demonstrated that the catalytic region of tTG is only of minor antigenicity and that most of the autoantibodies are directed against the non-catalytic amino and carboxyterminal region. ${ }^{32}$ One reason for this could be that in vivo the enzyme is usually substrate-bound and thus the catalytic centre is concealed from the immune system. Thus, only preincubation of tTG with the monoclonal antibody CUB 7402 , which is directed to the catalytic centre of tTG, almost completely blocked tTG activity.

The results with purified autoantibodies seem relevant for the situation in vivo, since no significant high molecular serum components are expected in the lamina propria. Therefore, we suggest that the inhibitory effect of anti-tTG autoantibodies is of minor biological importance in vivo. This conclusion is underlined by the fact that incomplete inhibition of tTG activity still allows highly efficient incorporation of cadaverine into gliadin when the reaction was performed for a longer time period. The increased mucosal tTG activity seems to play a central role in the pathogenesis of CD. Since this enhanced enzymatic activity in CD can not be completely blocked by patients' anti-tTG autoantibodies, the search and use of efficient inhibitors to reduce the pathologically increased tTG activity may be a viable novel treatment approach for $\mathrm{CD}^{31}$

\section{ACKNOWLEDGEMENTS}

We thank Dr Chaitan Khosla for the kind gift of the recombinant tTG plasmid and Dr Norbert Blank, Medical Department III, FAU Erlangen-Nuernberg for the introduction in measurement with the fluorometric PTI instrument.

\section{Authors' affiliations}

W Dieterich, D Trapp, B Esslinger, M Leidenberger, E Hahn, D Schuppan, Department of Medicine I, University of ErlangenNuernberg, Germany

J Piper, Department of Chemical Engineering, Stanford University, Stanford, USA

This study was supported by grants Schu 646/11-2 from the Deutsche Forschungsgesellschaft and by grants of the commission of the European Communities, Celiac EU-cluster program "Quality of Life and Management of Living Resources, QLRT-1999-00037", as well as NIH grant DK063158.

\section{REFERENCES}

1 Trier JS. Celiac sprue. N Engl J Med 1991;325:1709-19.

2 Marsh MN. Gluten, major histocompatibility complex, and the small intestine: a molecular and immunobiologic approach to the spectrum of gluten sensitivity ('celiac sprue'). Gastroenterology 1992;102:330-54.

3 Bürgin-Wolff A, Berger R, Gaze H, et al. $\lg G$, $\lg A$ and $\lg E$ gliadin antibody determinations as screening test for untreated coeliac disease in children, a multicentre study. Eur J Pediatr 1989;148:496-502.

4 Troncone R, Ferguson A. Anti-gliadin antibodies. J Pediatr Gastroenterol Nutr $1991 ; 12: 150-8$.

5 Dieterich W, Ehnis T, Baver $M$, et al. Identification of tissue transglutaminase as the autoantigen of celiac disease. Nat Med 1997:3:797-801.

6 Folk JE, Cole PW. Transglutaminase: mechanistic features of the active site as determined by kinetic and inhibitor studies. Biochim Biophys Acta 1966; 122:244-64

7 Folk JE, Chung SI. Transglutaminases. Meth Enzymol 1985;113:358-75.

8 Molberg $\varnothing$, McAdam SN, Koerner R, et al. Tissue transglutaminase selectively modifies gliadin peptides that are recognized by gut-derived $T$ cells in celiac disease. Nat Med 1998;4:713-17.

9 Van de Wal Y, Kooy Y, van Veelen $P$, et al. Selective deamidation by tissue transglutaminase strongly enhances gliadin-specific T cell reactivity. J Immunol 1998; 161:1585-8.

10 Anderson RP, Degano P, Godkin AJ, et al. In vivo antigen challenge in celiac disease identifies a single transglutaminase-modified peptide as the dominant A-gliadin T-cell epitope. Nat Med 2000;6:337-42.

11 Arentz-Hansen H, Körner R, Molberg $\varnothing$, et al. The intestinal T cell response to $\alpha$-gliadin in adult celiac disease is focused on a single deamidated glutamine targeted by tissue transglutaminase. J Exp Med 2000;191:603-12.

12 Vader W, de Ru A, van der Wal Y, et al. Specificity of tissue transglutaminase explains cereal toxicity in celiac disease. J Exp Med 2002; 195:643-9

13 Vader W, Kooy Y, Van Veelen P, et al. The gluten response in children with celiac disease is directed toward multiple gliadin and glutenin peptides. Gastroenterology 2002;122:1729-37.

14 Arentz-Hansen H, McAdam SN, Molberg O, et al. Celiac lesion T cells recognize epitopes that cluster in regions of gliadins rich in proline residues. Gastroenterology 2002;123:803-9.

15 Shan L, Molberg $\varnothing$, Parrot I, et al. Structural basis for gluten intolerance in celiac sprue. Science 2002;297:2275-9.

16 Fleckenstein B, Molberg O, Qiao SW, et al. Gliadin T cell epitope selection by tissue transglutaminase in celiac disease. J Biol Chem 2002;277:34109-16.

17 Dieterich W, Laag E, Schöpper H, et al. Autoantibodies to tissue transglutaminase as predictors of celiac disease. Gastroenterology 1998;115:1317-21.

18 Sulkanen S, Halttunen T, Laurila K, et al. Tissue transglutaminase autoantibody enzyme-linked immunosorbent assay in detecting celiac disease. Gastroenterology 1998;115:1322-8.

19 Brusco G, Izzi L, Corazza GR. Tissue transglutaminase antibodies for coeliac disease screening. Ital J Gastroenterol Hepatol 1998;30:496-7.

20 Seissler J, Borns S, Wohlrab U, et al. Antibodies to human tissue transglutaminase measured by radioligand assay: evidence for high diagnostic sensitivity for celiac disease. Horm Metab Res 1999;31:375-9.

21 Trevisiol C, Ventura A, Baldas $V$, et al. A reliable screening procedure for coeliac disease in clinical practice. Scand J Gastroenterol 2002;37:679-84.

22 Bürgin-Wolff A, Dahlbom I, Hadziselimovic F, et al. Antibodies against human tissue transglutaminase and endomysium in diagnosing and monitoring coeliac disease. Scand J Gastroenterol 2002;37:685-91.

23 Halttunen T, Mäki M. Serum immunoglobulin A from patients with celiac disease inhibits human T84 intestinal crypt epithelial cell differentiation. Gastroenterology 1999;116:566-72.

24 Keaveny AP, Offner GD, Bootle E, et al. No significant difference in antigenicity or tissue transglutaminase substrate specificity of Irish and US wheat gliadins. Dig Dis Sci 2000;45:755-62.

25 Esposito C, Paparo F, Caputo I, et al. Anti-tissue transglutaminase antibodies from coeliac patients inhibit transglutaminase activity both in vitro and in situ. Gut 2002;51:177-81.

26 Piper JL, Gray GM, Khosla C. High selectivity of human tissue transglutaminase for immunoactive gliadin peptides: Implications for celiac sprue. Biochemistry 2002:41:386-93.

27 Lorand L, Lockridge OM, Campbell LK, et al. Transamidating enzymes. II. A continuous fluorescent method suited for automating measurements of factor XIII in plasma. Anal Biochem 1971;44:221-31.

28 Casadio $R$, Polverini $E$, Mariani $P$, et al. The structural basis for the regulation of tissue transglutaminase by calcium ions. Eur J Biochem 1999;262:672-9. 
29 Ichinose A, Bottenus RE, Davie EW. Structure of transglutaminase. J Biol Chem 1990;265:13411-14.

30 Hansson $T$, Ulfgren AK, Lindroos $E$, et al. Transforming growth factor- $\beta$ (TGF$\beta$ ) and tissue transglutaminase expression in the small intestine in children with coeliac disease. Scand J Immunol 2002;56:530-7.
31 Schuppan D, Hahn EG. Gluten and the gut-lessons for immune regulation. Science 2002;297:2218-20.

32 Seissler J, Wohlrab U, Wuensche C, et al. Autoantibodies from patients with coeliac disease recognize distinct functional domains of the autoantigen tissue transglutaminase. Clin Exp Immunol 2001;125:216-21. 